\title{
Additive Manufacturing of Porous Metal
}

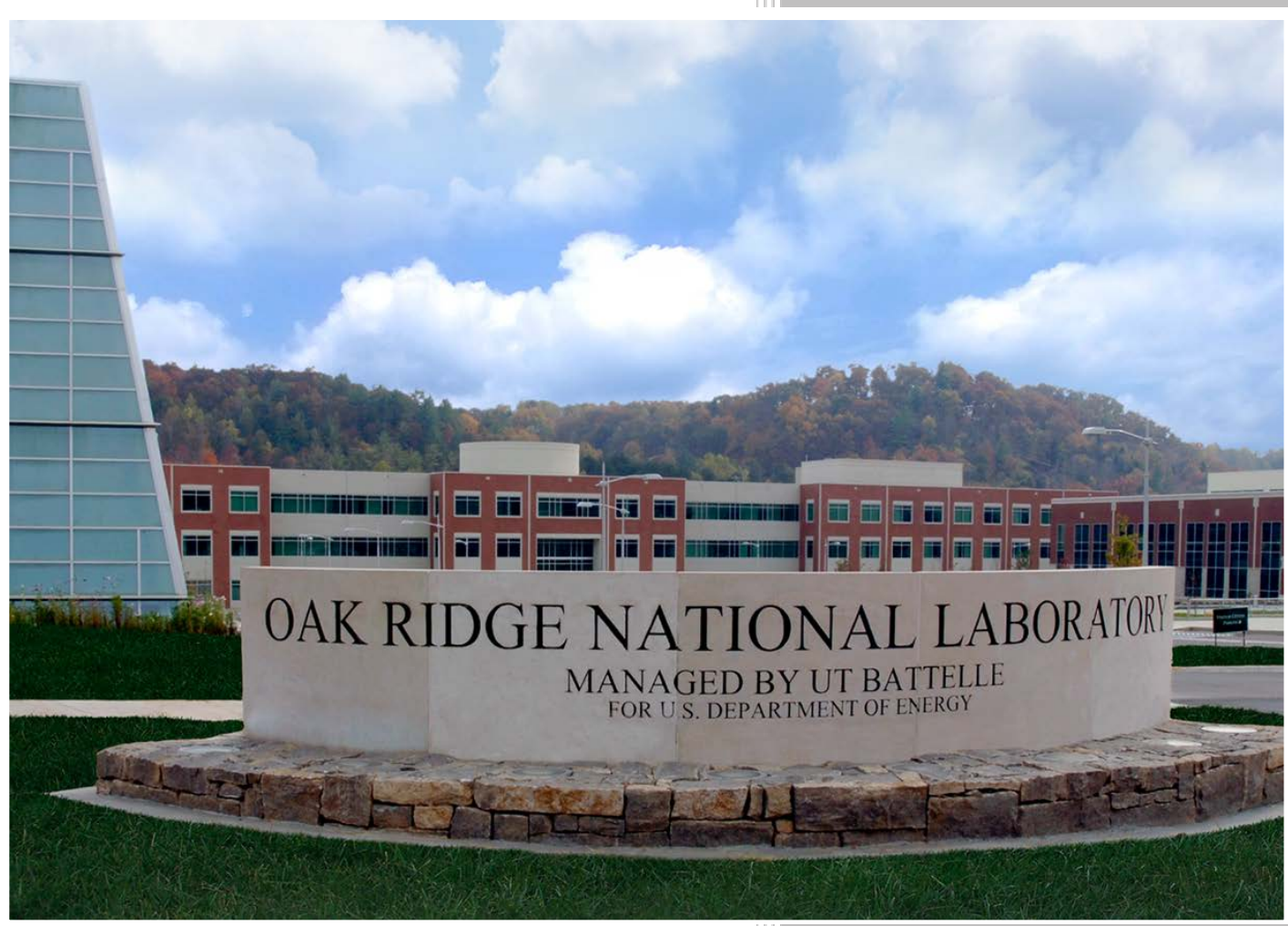

Ryan R. Dehoff

April 10, 2017

CRADA FINAL REPORT

NFE-15-05778

Approved for Public Release. Distribution is Unlimited. 


\title{
DOCUMENT AVAILABILITY
}

Reports produced after January 1, 1996, are generally available free via US Department of Energy (DOE) SciTech Connect.

Website http://www.osti.gov/scitech/

Reports produced before January 1, 1996, may be purchased by members of the public from the following source:

\author{
National Technical Information Service \\ 5285 Port Royal Road \\ Springfield, VA 22161 \\ Telephone 703-605-6000 (1-800-553-6847) \\ TDD 703-487-4639 \\ Fax 703-605-6900 \\ E-mail info@ntis.gov \\ Website http://www.ntis.gov/help/ordermethods.aspx
}

Reports are available to DOE employees, DOE contractors, Energy Technology Data Exchange representatives, and International Nuclear Information System representatives from the following source:

Office of Scientific and Technical Information

PO Box 62

Oak Ridge, TN 37831

Telephone 865-576-8401

Fax 865-576-5728

E-mail reports@osti.gov

Website http://www. osti.gov/contact.htm|

This report was prepared as an account of work sponsored by an agency of the United States Government. Neither the United States Government nor any agency thereof, nor any of their employees, makes any warranty, express or implied, or assumes any legal liability or responsibility for the accuracy, completeness, or usefulness of any information, apparatus, product, or process disclosed, or represents that its use would not infringe privately owned rights. Reference herein to any specific commercial product, process, or service by trade name, trademark, manufacturer, or otherwise, does not necessarily constitute or imply its endorsement, recommendation, or favoring by the United States Government or any agency thereof. The views and opinions of authors expressed herein do not necessarily state or reflect those of the United States Government or any agency thereof. 
ORNL/TM-2017/137

CRADA/NFE-15-05778

Materials Science and Technology Division Advanced Manufacturing Office

\title{
Additive Manufacturing of Porous Metal
}

\author{
Authors \\ Ryan R. Dehoff (ORNL) \\ Michael M. Kirka (ORNL) \\ Christopher A. Marlar (Zero Point Frontiers Corporation) \\ Matthew R. Nuss (Zero Point Frontiers Corporation)
}

Date Published:

April 10, 2017

\author{
Prepared by \\ OAK RIDGE NATIONAL LABORATORY \\ Oak Ridge, Tennessee 37831 \\ managed by \\ UT-BATTELLE, LLC \\ for the \\ US DEPARTMENT OF ENERGY \\ under contract DE-AC05-00OR22725
}

Approved For Public Release 


\section{CONTENTS}

CONTENTS .
LIST OF FIGURES .
ACKNOWLEDGEMENTS
ABSTRACT
1. ADDITIVE MANUFACTURING OF POROUS METAL




\section{LIST OF FIGURES}

Figure 1: Inconel 718 build fabricated using variations in beam current and beam pulse time to investigate effect on porosity density.

Figure 2: a) Four mesh structures utilized in mesh cube array for their ability to control porosity density b) Top view of mesh cube array.

Figure 3: Example top view of porous disc fabricated in this work through electron beam melting..... 3

Figure 4: CAD model cutaway of the permeable disc revealing the sacrificial low density mesh

necessary to mitigate geometric inadequacies during fabrication.

Figure 5: Optical microscopy images depicting the variation in surface porosity as a function of beam

current and beam pulse time for the build shown in Figure 1.

Figure 6: Variation in porosity density of cubes fabricated in Figure 1 as a function of beam pulse

time and beam current based on image processing technique.

Figure 7: Comparison of various (image processing, liquid immersion, and gas pycnometer) density measurement techniques for samples taken across the diagonal of the build shown in Figure 1...........5

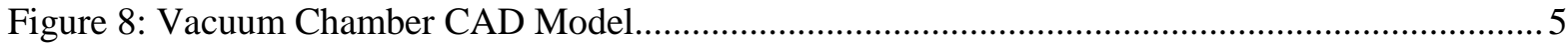

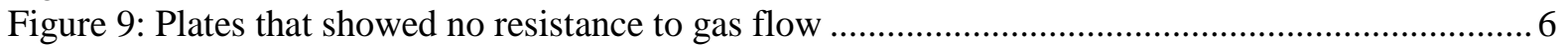

Figure 10: Plate with high resistance to gas flow............................................................................. 6 


\section{ACKNOWLEDGEMENTS}

This CRADA NFE-15-05778 was conducted as a Technical Collaboration project within the Oak Ridge National Laboratory (ORNL) Manufacturing Demonstration Facility (MDF) sponsored by the US Department of Energy Advanced Manufacturing Office (CPS Agreement Number 24761).

Opportunities for MDF technical collaborations are listed in the announcement "Manufacturing Demonstration Facility Technology Collaborations for US Manufacturers in Advanced Manufacturing and Materials Technologies” posted at http://web.ornl.gov/sci/manufacturing/docs/FBO-ORNL-MDF-2013-2.pdf. The goal of technical collaborations is to engage industry partners to participate in short-term, collaborative projects within the Manufacturing Demonstration Facility (MDF) to assess applicability and of new energy efficient manufacturing technologies. Research sponsored by the U.S. Department of Energy, Office of Energy Efficiency and Renewable Energy, Advanced Manufacturing Office, under contract DE-AC0500OR22725 with UT-Battelle, LLC. 


\begin{abstract}
Currently, helium is obtained through separation from natural gas. The current industrial process incurs significant costs and requires large energy resources to successfully achieve separation. Through utilizing Additive Manufacturing (AM) technologies it is possible to reduce both of these burdens when refining helium gas. The ability to engineer porosity levels within Inconel 718 discs for controlled separation of helium from natural gas was investigated. Arrays of samples fabricated using the electron beam melting process were analyzed for their relative porosity density. Based upon the measurements, full scale discs were fabricated, and subsequently tested to determine their effectiveness in separating helium from liquefied natural gas.
\end{abstract}

\title{
1. ADDITIVE MANUFACTURING OF POROUS METAL
}

This phase 1 technical collaboration project (MDF-TC-2015-077) was begun on August 14, 2015 and was completed on March 14, 2017. The collaboration partner Zero Point Frontiers Corporation (ZPFC) is a small business. The permeability of engineered porous Inconel 718 discs fabricated by electron beam melting was evaluated for helium separation from liquefied natural gas.

\subsection{BACKGROUND}

The primary areas of technical and research focus for ZPFC are space, energy, biotechnology, nanotechnology, and robotics. To date, advanced designs for components and assemblies for helium separation have been limited by manufacturability. These current processing techniques for helium separation are also costly. With the advent of additive manufacturing techniques new design avenues are now available through which ZPFC and ORNL sought to investigate the ability to engineer porosity within components to control the rate at which helium may be separated from liquefied natural gas.

\subsection{TECHNICAL RESULTS}

\subsubsection{Sample Fabrication}

To understand the influence of processing parameters available in the electron beam melting process on engineering porosity in Inconel 718, two build arrays of 16 cubes each were fabricated by electron beam melting using the ARCAM S12 at the ORNL Manufacturing Demonstration Facility (MDF). The first build array evaluated a point heat source strategy developed at ORNL. While initially intended for crystallographic texture control, the point heat source strategy was repurposed for designing variable conditions of engineered porosity into the test cubes. This first build is shown in Figure 1, where the electron beam current and beam pulse time were varied. The second sample array consisted of a variety of mesh structures (Figure 2a) with varying strut thicknesses to control density levels. An overview of this build is shown in Figure 2b. 


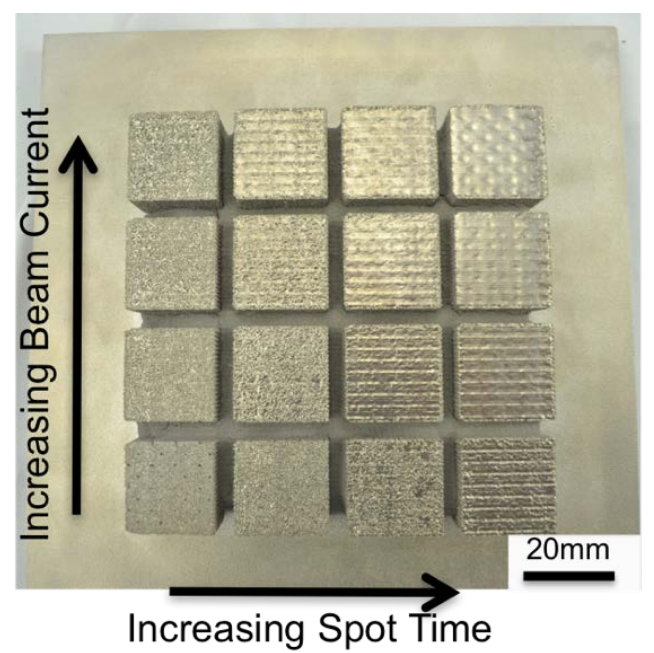

Figure 1: Inconel 718 build fabricated using variations in beam current and beam pulse time to investigate effect on porosity density.

a)
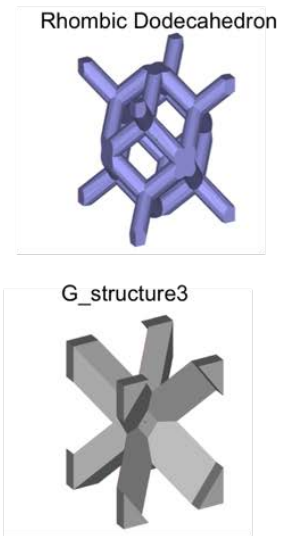

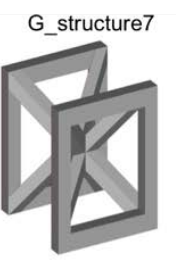

Dode Thin

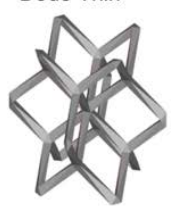

b)

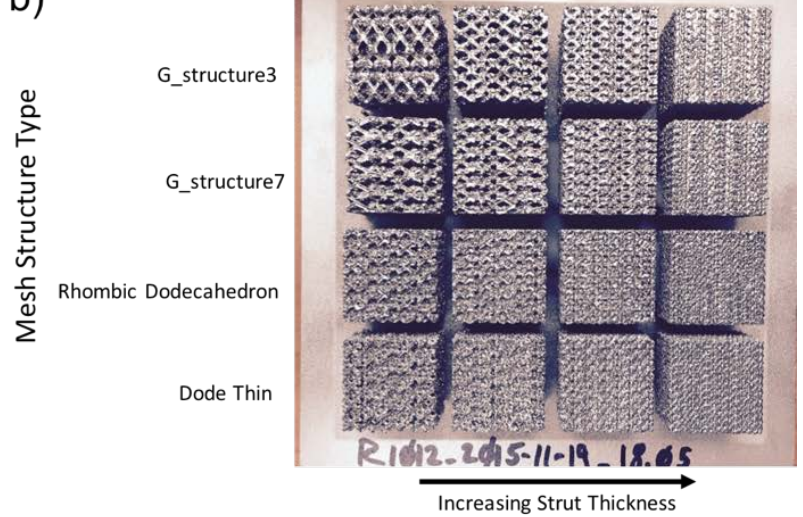

Figure 2: a) Four mesh structures utilized in mesh cube array for their ability to control porosity density b) Top view of mesh cube array.

Based on the results of the engineered porosity parameter space sweep, permeable discs of various degrees of engineered porosity were fabricated like the one shown in Figure 3. A cutaway of the discs is shown in Figure 4. The discs are comprised of a central solid ring, followed by a sacrificial highly porous center closest to the plate before transitioning to a center of engineered porosity density. The sacrificial porous layer was necessary to avoid distortion and maintain geometric accuracy of the discs during fabrication. The four pillars surrounding the edges of the build plate are also sacrificial and necessary for minimizing warpage of the build plate during the fabrication process. Additional to the porous plates, a plate containing a solid center was also fabricated to utilize as a baseline from which to measure the capability of the engineered pours discs. 


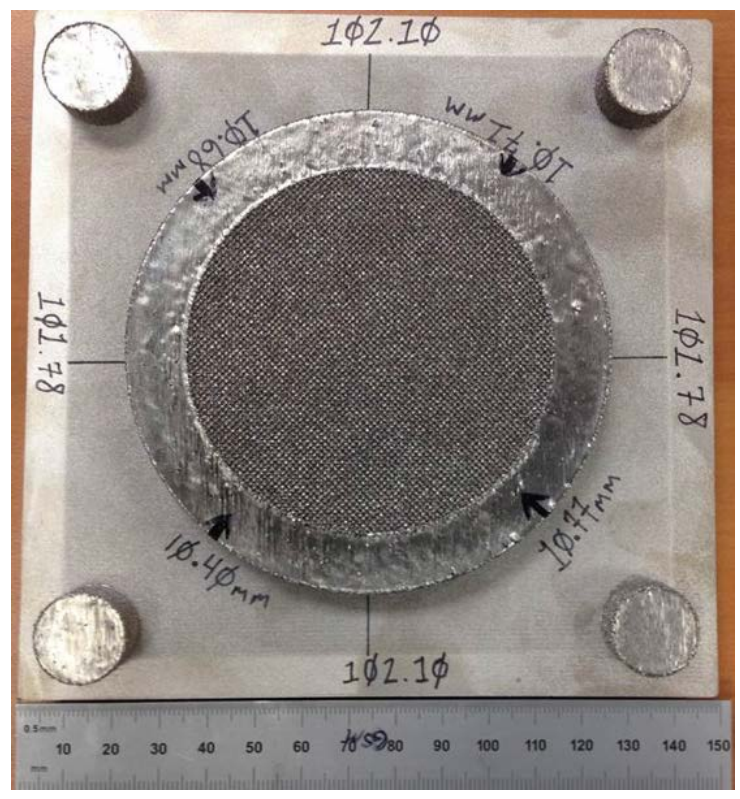

Figure 3: Example top view of porous disc fabricated in this work through electron beam melting.

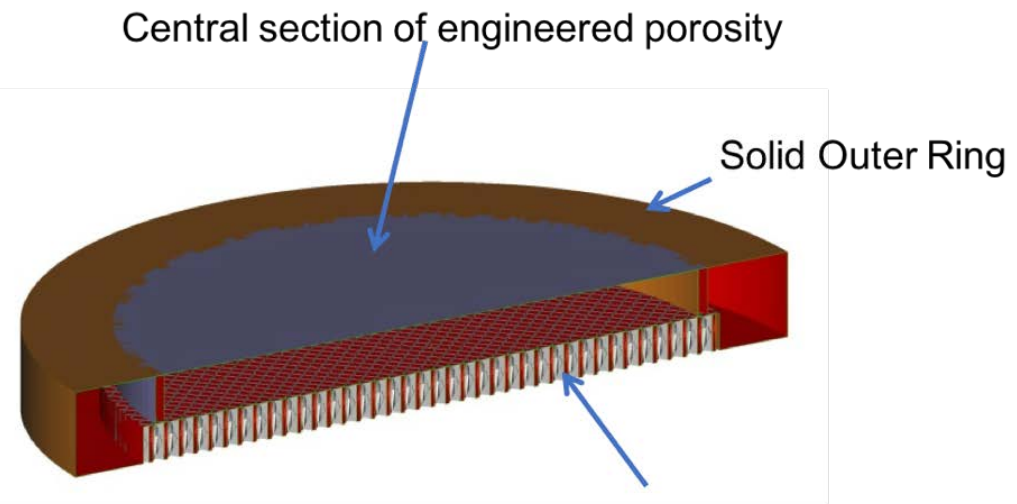

Underlying Sacrificial Mesh Support Structure

Figure 4: CAD model cutaway of the permeable disc revealing the sacrificial low density mesh necessary to mitigate geometric inadequacies during fabrication.

\subsubsection{Engineered Porosity Characterization}

Cubes fabricated using the point heat source method were down selected for further investigation and analysis prior to fabricating the full scale porous discs (Figure 1). Various methods were used to ascertain the density of porosity and level of connectivity of the porosity. These included

- Image processing: The detection of porosity through contrast differences between the bulk and pores.

- Liquid immersion: Compare the measured bulk density to the theoretical density of the material.

- Gas pycnometer: Correlate the volumetric change of a pressurized gas to interconnected and surface porosity in a bulk material.

For the intended application as helium separator plates, it is desirable to not have 
interconnected porosity throughout the bulk structure.

Shown in Figure 5 are representative optical micrographs of the variation of porosity observed within the cubes as both beam current and spot time change. Note the images in the lower left and upper right hand corners of Figure 5 are lacking due to the bottom left being nearly 100\% porous and the upper right being nearly 100\% dense. Figure 6 depicts topological maps of the average porosity levels for each of the cubes as determined through using image analysis. To verify the validity of the image analysis technique for determining apparent porosity levels, cubes taken along the diagonal were subjected to the two additional methods discussed previously, liquid immersion, and gas pycnometer. The results are presented in Figure 7. Overall, the imaging methodology was found to be consistent with the liquid immersion technique, but the gas pycnometer results indicated the lack of porosity. The lack of gas flow through the material however indicated the lack of connected of porosity within the material. From these results, the conditions for fabricating four full scale permeable membrane discs were chosen.

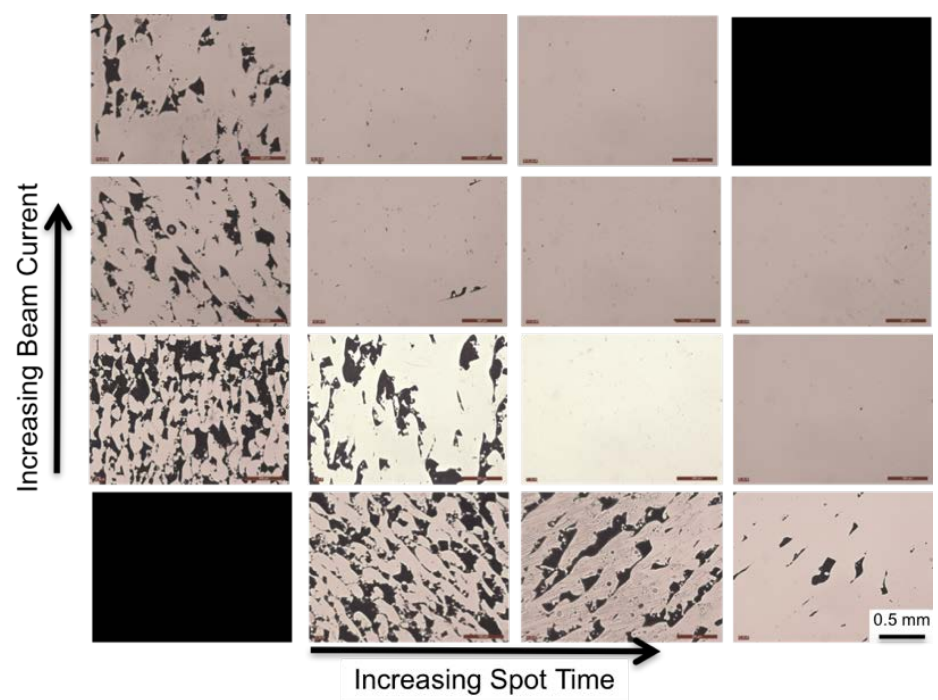

Figure 5: Optical microscopy images depicting the variation in surface porosity as a function of beam current and beam pulse time for the build shown in Figure 1.

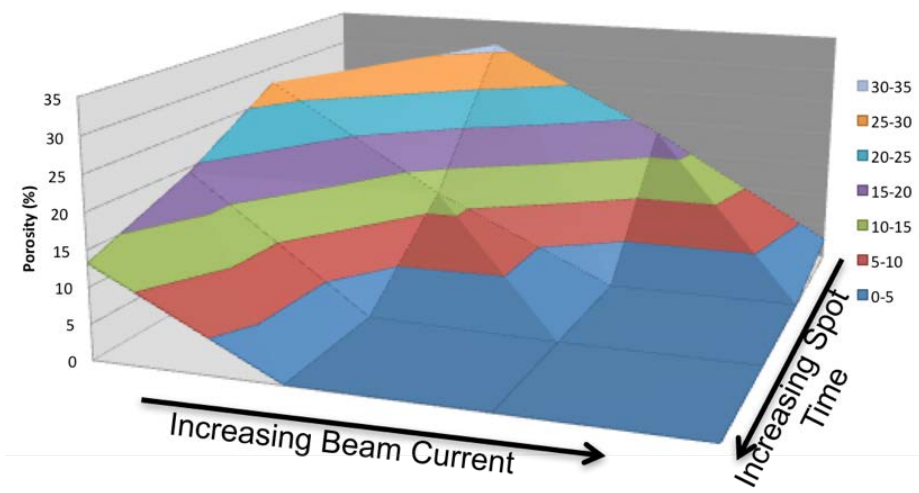

Figure 6: Variation in porosity density of cubes fabricated in Figure 1 as a function of beam pulse time and beam current based on image processing technique. 


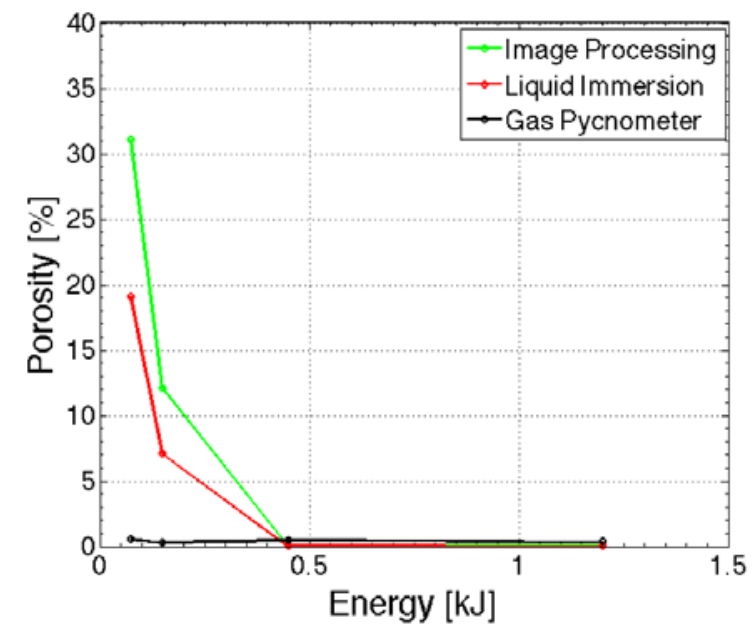

Figure 7: Comparison of various (image processing, liquid immersion, and gas pycnometer) density measurement techniques for samples taken across the diagonal of the build shown in Figure 1.

\subsubsection{Permeable Plate Evaluation}

To test the permeability of the plates, ZPFC designed a custom vacuum chamber as seen in Figure 8. One chamber has a connection to a vacuum pump while the other chamber is open to ambient air through a valve. Four plates of varying porosity were tested to determine how well each plate allowed the passage of gas. The plates were nested between two sealed chambers and a vacuum was drawn in one chamber. The pressure was monitored in both chambers to determine how easily the plates allowed flow between the two chambers. All tests began with both chambers at ambient pressure and temperature.
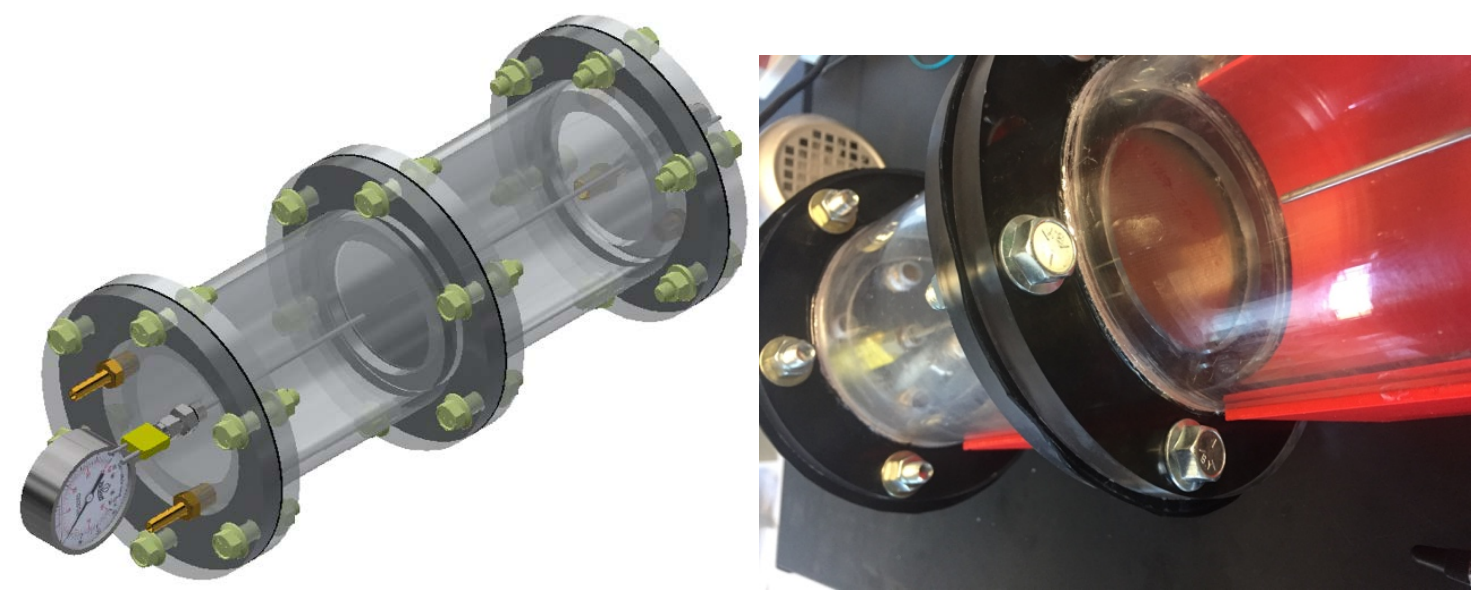

Figure 8: Vacuum Chamber CAD Model (left) and Actual Test Chamber (right) showing test plate installed

The three plates shown in Figure 9 did not hinder the passage of gas between the two chambers, and the pressure in both chambers dropped simultaneously. The plate shown in Figure 10 showed a significantly higher resistance to the passage of gas. The pressure in the vacuum side of the test assembly dropped much faster than the other side. However, even after turning off the vacuum pump, gas continued to flow through the plate at a slow rate causing the pressure in the vacuum side to rise 
while the pressure in the opposite side continued to drop until both sides were in equilibrium. A separate test was conducted using a plate shown in Figure 9 where the test assembly was turned vertical and the lower chamber was filled with water to test the sublimation properties of the plate. While the water did boil in the low pressure conditions, the temperature in the chamber never got low enough to hit the triple point of water so that ice could form on the plate and begin to sublimate.

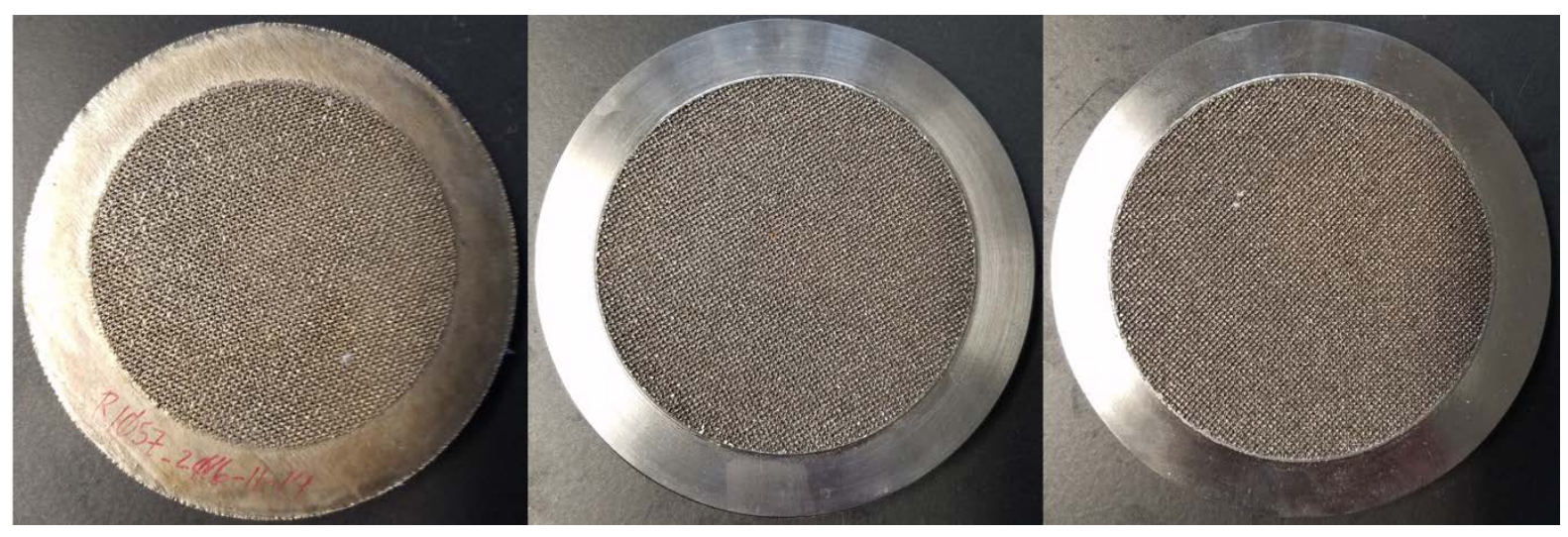

Figure 9: Plates that showed no resistance to gas flow

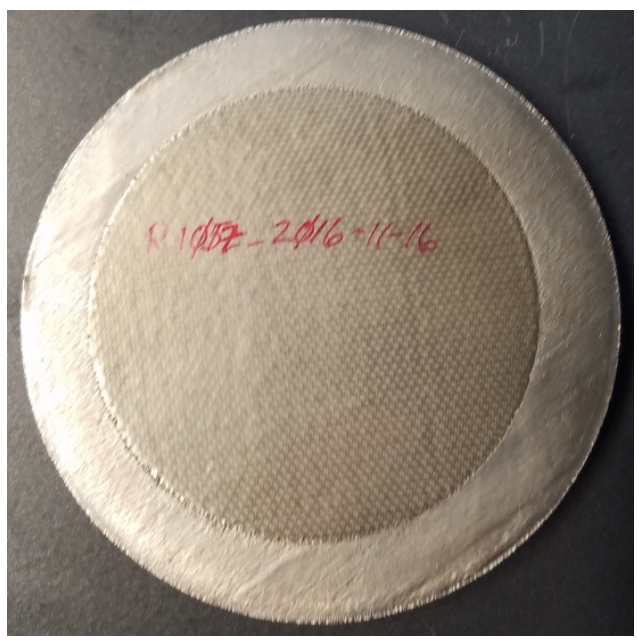

Figure 10: Plate with high resistance to gas flow.

\subsection{IMPACTS}

The research acted as a real-world proof of concept and allowed for the exploration of an area of material science that has little previous work. The production of porous metal materials allows for some very interesting manufacturing of structural components that may require precision balancing that does not synchronize with a volume of uniform density as well as any number of other unique properties. However, this experiment showed the difficulty in reliably producing porous metal materials with a specific permeability required to act as a gas filter.

ZPFC does not have plans to move forward with this approach at this time. 


\subsection{CONCLUSIONS}

Porosity levels within the EBM fabricated Inconel 718 material were successively controlled, the porosity levels necessary to make the membranes achieve the proper permeability was below the threshold of control of the EBM process. The plates with porosity levels similar to those shown in Figure 9 have such a high permeability to gasses that they will not be suitable for the application of filtering helium from natural gas. However, in the presence of a stronger vacuum, it is believed that the high permeability plates would be a suitable substitute for current sublimator plates. The plate in Figure 10 that was initially believed to be a failure actually displayed properties suitable to potentially filter helium from natural gas. 


\section{PARTNER BACKGROUND}

Zero Point Frontiers Corporation (ZPFC), a Huntsville, Alabama-based veteran-owned small business, was founded in 2008 to be focused on and designed for the future, with the goal of performing technical research and development in space, energy, biotechnology, nanotechnology, and robotics. ZPFC initially assisted numerous government and commercial agencies and supported multiple vehicle and technology trade studies for the Ares Launch Projects and later the Space Launch System. ZPFC's work was also integral to NASA's efforts to identify the key requirements, configurations, missions, and propulsion systems needed to shape heavy-lift launch vehicles for human missions beyond Low-Earth Orbit as well as providing decision support for NASA's ExtraVehicular Activity Office. 